\title{
INDEX OF PLACES
}

Actium 6, 69, 83,

Aelia Capitolina 114, 115, 233, 345

Ain Tounga 304

Akraiphia 25, 27, 161-164, 170, $171,173,177,183$

Alexandria 89, 114, 311

Alia 204367

Altava 115, 118

Amastris 14

America 267

Anazarbos 114, 117-119

Ancyra 204

Antemnae 125

Antioch 114, 216, 217, 218

Antioch (Psidia) 327-329, 334$336,338,345,346$

Antium 345

Apamea 209

Aphrodisias 11, 25, 26

Aquileia 123, 267

Amiternum 267

Asisiun 114

Athens 7, 8, 22, 27,28, 190, 191, 314,315

Atina 261

Attaleia 115, 118

Augusta Trevorum 242

Balboura 320

Bassae 314

Beirut 17, 35

Beroia 18, 320

Bithynion 12

Bonn 213

Brundisium 133

Burdigala 264

Caesarea 261, 270, 272-275, 281

Caesarea Maritima 216, 217 , 221, 222, 224, 225, 228, 229, 231-235
Caesarea Philippi 35

Cairo 17

Cales 132

Caparcotna 218

Capua 45, 49

Carrhae 56

Carthage 48, 264, 273

Chalkis 27

Chios 198

Cillium 275

Civitella 267

Claros 206, 207

Cnidus see Knidos

Colonia Aelia Capitolina see Aelia Capitolina

Colonia Caesarea Antiochea see Antioch in Psidia

Colonia Claudia Ara

Agrippinensium 215, 264

Colophon 205

Constantinople 146, 234, 316

Copenhagen 262

Corbridge 261

Corfinium 261

Corinth 308

Cosa 35

Cuicul 290

Cumae 132

Cyme 199

Cyrene 24

Cyzicus 190

Delos 7, 21

Der al-Qalat 152

Didyma 175

Djebel Bou Kornein 294

Dura-Europos 16

Dyrrhachion 22

Emesa 111-115, 117, 118, 151

Emmaus 233

Empel 299 
Ephesus 123, 136, 140, 178, 190, 191, 201, 208, 209, 216

Epidauros 12

Esna 356

Falerii Veteres 345

Faustinopolis 116-118

Fidenae 125, 132

Flavia Neapolis 209

Furfo 267

Gerizim 117, 118

Gytheion 10

Heliopolis 345

Henchir el-Hami 288, 290, 302

Henchir es-Srira 289

Henchir Ghayadha 288

Henna 307

Herculaneum 132

Hierapolis 203, 206, 208

Hierapolis-Castabala 114, 117 , 118

Hippo Regius 290, 305

Hispellum 345

Idebessos 199

Iguvium 129

Irni 251, 343

Iuliopolis 114,118

Jerusalem 191, 217-219, 226, $227,233,245$

Karakuyu 329

Kaunos 27

Kessel 299

Kibyra 207, 209

Klaros 15, 16, 22, 23

Knidos 26, 317

Knossos 335

Kula 18

Lagina 175
Lamasba 114

Laodicea ad Mare 114, 115, 117, 118

Laodicea ad Lycum 200, 203, 206

Lepcis Magna 260

Leukopetra 18

Lindos 12

London 19

Lucca 36

Macedonia 3, 5

Magnesia 203

Magnesia ad Sipylum 186, 206

Mainz 16

Malpensa 251

Mandragoreis 203

Marathon 27

Masada 219

Matineia 12

Megalopolis 314

Menzel Harb 288

Milan 36, 269, 279

Milas 208

Miletos 188

Minturnae 345

Mopsouhestia 27

Myra 206

Narmouthis 357

Naulochus 69

Neapolis 102, 114, 115, 117, 324

Nephelion 201, 206

Nicea 42

Nicivibus 292, 293

Nicopolis 233

Nijmegen 213

Nicomedia 3, 4, 114, 117-119

Nola 132

Oinoanda $13,15,123,136,140$

Olympia 309, 310, 313, 316-

$318,322-324$

Ossigi 266 
Ostia 123-141

Panamara 175, 178

Paneas see Caesarea Philippi

Panoias 22

Paphlagonia 22

Patavium 126

Pergamum 58, 110, 203, 207, 320

Perge 22

Phigaleia 314

Philippopolis 320

Pisa 80

Plataia 27

Pompeii 126, 132, 261, 262, 264

Pontos 22

Portus 133, 134

Praeneste 267

Pruse 185, 188, 195

Prymnessos 185

Ptolemais 24

Pupput 269- 276

Puteoli 132

Pyleitai 200, 203

Rennes 109

Rhodes 200

Rome 3-9, 16, 21, 29, 36, 43, 46, $50,53,55,58,61-66,68-70$, 73, 77, 97, 99, 100, 102, 111,114, 116, 118, 123-127, 129, 131-138, 141, 144-147, $149,154,155,157,161,188-$ $190,207,214,215,218,220-$ $222,224,225,227,228,232-$ 234, 243, 246-252, 256, 260 262, 264, 265, 277, 295, 296, $327,338,339,365$

Saguntum 19

Saintes 243

Salpensa 251

Samos 207, 317

Sardes 115, 116, 118, 119, 206
Sarmizegetusa 215

Satafis 269, 270, 272, 276, 278, 281-284

Scythopolis 232

Sétif 282

Sfax 271

Siagu 288

Sitifis 270, 271, 273, 282

Smyrna 185, 191, 195

Stratonikeia 22

Sulmo 261

Syene 42, 214

Takina 190

Teanum Sidicinum 264

Teboursouk 291

Tebtynis 357

Tel Dan 153

Tel Halif 153

Teos 22

Thaenae 271

Thala 291

Thamugadi 270, 271, 275

Theveste 271

Thignica 289

Thuburnica 288, 290

Thugga 271, 284

Thyatira 116, 118, 188, 207

Thysdrus 248, 297

Timgad 301

Tipasa 270, 272-275, 278

Tlos 199

Tubusuctu 264

Tunis 262, 279

Tyros 152

Urso 246, 247, 337, 343

Vesontio 264

Vienna 12

Zarbos 117, 118

Zela 206

Zucchabar 291 